\title{
A Meso-scale Habitat Classification Method for Production Modelling of Atlantic Salmon in Norway
}

\author{
P. Borsányi \& K. Alfredsen ${ }^{a}$, A. Harby ${ }^{b}$, O. Ugedal ${ }^{c}$, C. Kraxner ${ }^{d}$ \\ Corresponding author : Péter Borsányi: peter.borsanyi@ntnu.no
}

\begin{abstract}
Meso-scale classification of rivers has been used for decades in hydrology and ecology. Recent research has demonstrated a large potential for using this in ecohydraulics. Habitat modellers have to look at complex systems (e.g. catchments), where problems inherent in applying models developed for small scales applied for larger scales need to be overcome. The use of hydro-morphological units linked to meso-habitats extends the information and helps bypassing the problems arising from scale alteration. The process is called upscaling.

This paper presents a physical approach for mesohabitat assessment in small to medium sized rivers, with the purpose of serving as a scaling tool for physical habitat information from micro-scale to macro-scale. Results of the assessment are to be used for population modelling of juvenile Atlantic salmon (Salmo salar). The system has been tested in Norway and in Great Britain on rivers of various sizes, has a flexible structure, so that it can be adapted to different situations and problems and is also rapid regarding habitat mapping.
\end{abstract}

Key words. - mesohabitats; habitat mapping; scaling; population modelling; hydromorphology

\section{INTRODUCTION}

The method presented in this paper introduces a scaling method for habitat modelling applications. The work forms a part of a larger govern- ment-funded research project : "Links between meso-habitat classes, food consumption, growth and production of juvenile Atlantic salmon". It is being undertaken by the Norwegian Institute for Nature Research (NINA), the

\footnotetext{
${ }^{a}$ Norwegian University of Science and Technology, Department. of Hydraulic and Environmental Engineering, S.P. Andersensvei 5. N-7491 Trondheim, Norway.

${ }^{\mathrm{b}}$ Sintef Energy Research, Sem Sælandsvei 11, N-7465 Trondheim, Norway.

'Norwegian Institute for Nature Research (NINA), Tungasletta 2, N-7485 Trondheim, Norway.

d University of Innsbruck, Faculty of Civil Engineering and Architecture, Institute of Hydraulic Engineering, Technikerstraße 13, A-6020 Innsbruck, Austria.
} 
Norwegian University of Science and Technology (NTNU), Sintef Energy Research Ltd, Norway (SEFAS), University of Michigan, USA and Anadromous Fish Research Center, U.S. Geological Survey, USA.

The study detailed below establishes a meso-scale river habitat classification method which allows mesoscale channel features to be linked to productivity of salmon fry and parr. Future phases of the overall project in turn, would allow an assessment of the variation in habitat quality within and between rivers for smolt production. To achieve this ultimate goal, methods for scaling up from established microhabitat models to mesohabitat classes are needed to be developed. The primary objective of the larger project is thereby the development of meso-habitat classes by upscaling from established microhabitat models :

1. developing a classification method on purely hydro-morphological features

2. finding objective methods to apply this to rivers

3. developing methods to characterise spatial and temporal class variations

The future objective following this phase is the comparisons of relative growth, food consumption and growth efficiency of fry and parr in different habitat classes within and among rivers. Other applications would also be related to practical river characterisations.

\section{POPULATION MODEL - NORSALMOD}

This chapter gives a brief introduction to the Norwegian Salmon Population Model, in order to help understanding the reasons and the needs for which the mesohabitat classification system was developed.

The salmon population model NORSALMOD is developed to simulate the population development of Atlantic salmon from spawning to out migrating smolt phase controlled by physical and biological factors. The model can handle multiple yearclasses simultaneously. The model has two main components :

1. A temperature based growth and development model that simulates egg maturation, alevin development and parr growth using temperature formulations. Work is done to develop this model to suit different temperature regimes found in various Norwegian rivers. The setup includes data for size distributions in each year-class and it computes the number of smolts from each year-class.

2. A habitat based distribution and mortality model that uses a mesohabitat characterization of the river to predict spawning areas, parr distribution, parr movement and habitat suitability. Data from the functional links programme will be used to characterize the available habitats depending on biological criteria. Based on the need for classes identified in the population 
model the meso-habitat method classification used will be simplified.

In addition the model consists of a temperature component and a hydraulic component that handles flow routing and stage computations at certain locations. The structure is object based and the river system description is flexible on the number of components and on how they are linked. Since one of the objectives of the development is to describe effects of river regulations on the population the base structure can also handle reservoirs with gates, spillways and release plans. The base structure of the method is shown on Figure 1.

In order to achieve this goal a new methodology had to be developed. The method presented in this paper itself is only the first phase of the larger project, which deals with the links between meso-habitat classes, food consumption, growth and production of juvenile Atlantic salmon, with the ultimate goal of finding bottlenecks and aids for the development of a population of salmon under different flow conditions.

\section{BACKGROUND AND THEORY}

The Instream Flow Incremental Methodology (IFIM) emerged first from empirical, later more rational but still semi-objective solutions to enable more environmentally sound management of rivers (Stalnaker et al. 1995). In our strategy we divide the controlled river into units that are suitable for modelling in terms of

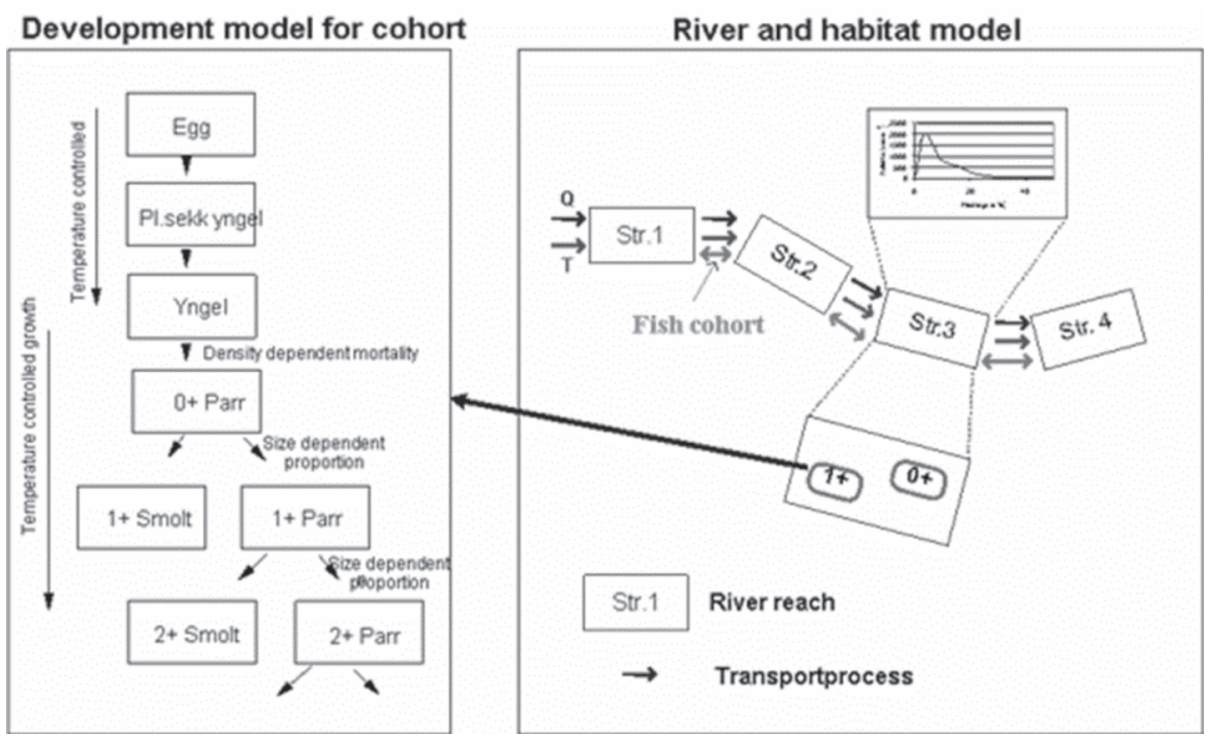

Fig. 1. - Norsalmod population model. 
scale and detail. In the traditional PHabSim method (which is used in the IFIM) these units are segments with some $\mathrm{km}$ in length and representative reaches with some $100 \mathrm{~m}$ in length are chosen within these. These reaches are then measured in detail in order to describe physical habitat characteristics, and to enable hydraulic modelling of conditions not covered by measurements. For the first level of division macro-scale hydrological and morphological features are looked at, for the latter detailed morphology is considered (Bovee 1982). Other methods using different procedure for the same purpose are also available (Alfredsen 1997). Both methods mentioned, and also others available result in a similar problem, that in order to reach a scale which is suitable for modelling, only a little portion of the river system can be examined, which in addition is chosen non-objectively, and thereby a high degree of uncertainty arises when returning to the "original" river scale for management applications (Maddock 1999). This is because that there is a difference between the level of river management and the level of models; river management mostly operates at catchment or river sector level, while modeling, like PHabSim uses the much smaller site level. Therefore the units of the two operations differ and results from small scale models are assumed to be valid at those larger scales.

Also there is a clear need for time and labour (and cost) effective habitat modelling methods in general, to fulfil the increased need of river habitat surveys and other similar applications. For example the implementation of the European Water Framework Directive requires a general and a continuously updated information database on the ecological conditions of watercourses (EU 2000). It is understood that rare or non measurable flow conditions have to be modelled for this task.

Finally when finding sufficient units for describing the ecosystems, one would find that these items differ from those used both in river management and habitat modelling, but would be close to meso-sized hydro-morphological classes (Kemp et al. 1999).

From these it seems natural to employ an intermediate method in between the macro- (river) scale, and the micro- (hydraulic/habitat modelling) scale to provide an objective river segment/reach classification method and thereby ensure proper representation of the various formations of morphology and habitat and enable transferability between rivers (Maddock \& Bird 1996). The method needed should employ meso-sized classes that are based on river morphology, and habitat characteristics, should also be consistent and reproducible (objectivity), easy and cheap to employ in terms of labour and costs.

First versions of such methods are the widely spread riffle-run-pool methods (Raven et al. 1998; Rosgen 1996). These fulfil the criteria of fast/ cheap observation and partly the others as well, although their 
reproducibility has been criticized (Jowett 1993). Also, since stream segments are classified into three categories only, a very simple layout is achieved, which may not be applicable for a wide range of applications, therefore is not flexible. Riffle-runpool methods are very useful for the specific purpose they were created for, namely to serve as a general information tool with solid, rigorous design and construction, but their possibilities to expand to other fields are limited.

Newer alternatives presenting solutions for large scale habitat assessment by mesohabitat mapping (e.g. Maddock \& Bird 1996; Parasiewicz 2001) involve physical measurements of each meso-habitat class mapped, therefore they are still time consuming. Proper physical description of class features obviously allow well founded analysis, but on the contrary they suffer from being ineffective concerning time and perhaps labour as well.

Hence we decided to develop an individual system which is more detailed and flexible than the traditional physical approaches and also faster than the newer versions.

\section{MESO-SCALE HYDRO- MORPHOLOGICAL CLASSIFICATION METHOD IN NORWAY}

\section{General}

The method developed is based on review of literature for scale issues and meso-scale classification methods for various hydrological and ecological purposes. It builds on the widely applied riffle-run-pool methods, but aims to be more detailed, rapid in application, flexible and objective than the previous approaches. Actual verification of the method is on-going. For approaches which served as starting point for the project see e.g. Bisson et al. 1981; Cohen et al. 1998; Hardy 1995; Hawkins et al. 1993; Kershner \& Snider 1992; Mader et al. 1999; Rosgen 1996; Takahashi 1994; Vadas \& Orth 1998; Van Beurden \& Douven 1999.

The major criteria during development were that

- the method should be applicable to all Norwegian salmon rivers in general,

- no expert knowledge should be necessary for utilizing, and

- no special or sophisticated instrumentation should be needed to employ the method in any case.

It was also necessary to create a flexible structure, so that the method can adapt to initially unforeseen situations. In practice means, that the specialities of actual cases have to be considered, perhaps by adding unique criteria (e.g. new layers of information) to the scheme. This can only be varied within limitations, to preserve compatibility between the various approaches.

The describing factors of classes are decided to be water depth, surface pattern, surface gradient and surface velocity, thereby ten different 
classes are obtained. Practically impossible - which means naturally nonappearing or very rare - combinations are neglected. In addition, for each class, as a second layer of the classification scheme, substrate composition has to be noted (e.g. $70 \%$ cobble, $20 \%$ pebble, $10 \%$ sand or sizes of dominant/subdominant substrate with or without vegetation). The mapped sector of the river has to be divided into meso-scale sized classes as shown below.

Further on the classes are linked to meso-habitats by evaluating them with usual micro-habitat methods. Each class type present unique phys- ical characteristics and different behaviour of the individuals can be observed in them. Thereby analysis of rivers by means of hydro-morphological units can serve as starting point for population modelling, or detailed description of habitat distribution.

\section{Methodology}

The surface of the river is divided into triangular and quadratic units considering the four criteria noted above. A maximum of three units between cross sections are allowed (Figure 2). These are identified and are drawn to the paper or digital map.

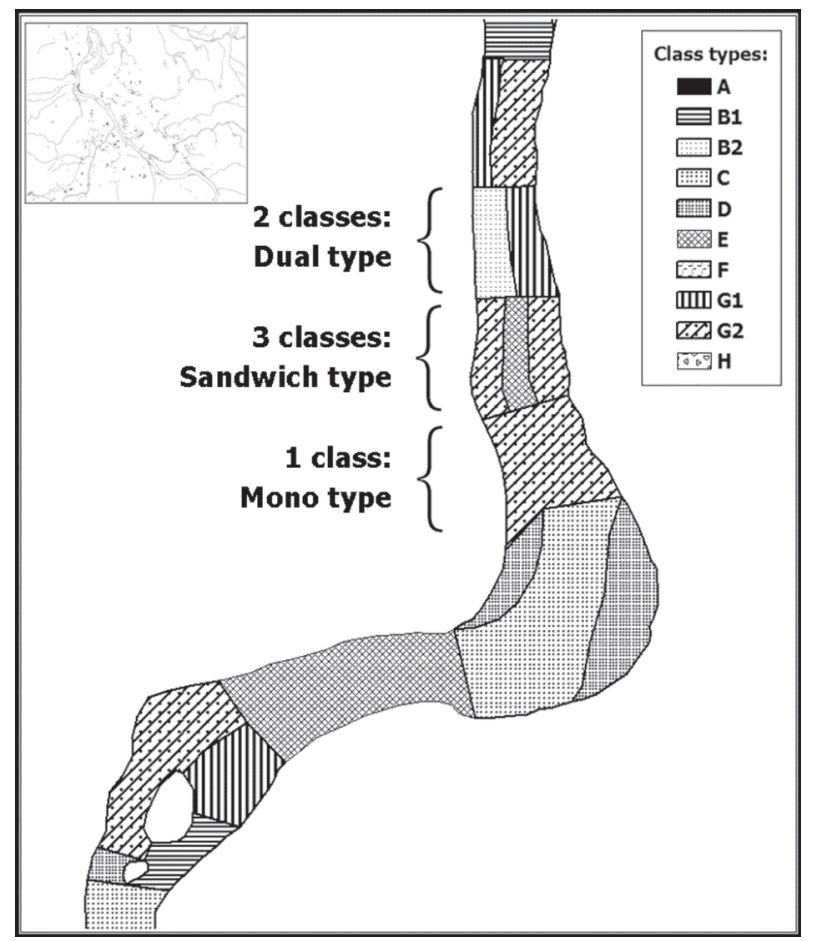

Fig. 2. - Explanation of class layout and configuration. 
The identification is carried out by visual observation and simple measurements following the decision tree below (Table I).

With the aim of objectivity, limits have to be applied to decision criteria such as "steep slope" or "fast flow". Definitions of these limits are not based on studies, they simply serve as internal standard throughout the applications. These numbers are not meant to be universal or valid for all possible tasks. We suspect that studies of larger rivers would require adjustment of these, however during our experiments they remained unchanged (Table II).

In order to carry out a successful field campaign, a map of the study sites is needed in advance in approximately 1:5000 scale. Together with the maps, which are used for drawing sketch layout of the classes in situ, sections and/or longitudinal profiles (used for regulatory purposes or flood design) are also useful.

\section{Analysis}

First the reaches are evaluated from a large perspective. Their overall class composition presented in pie-charts with occupied areas as per cent of total (as on Figure 9 in chapter "Results"), and basic statistics such as average areas, or overall areas of mesohabitat types (as on Figure 7 and Figure 8 in chapter "Results") are compared at mapped flows and reaches. These give a first impression of catchment shape (from an ecological point of view) and habitat composition together with habitat variation among and within reaches at different flows.

Class accumulation charts (as on Figure 10 and Figure 11) refine the large perspective by physically identifying longitudinal breakpoints or other similar characteristics of the reaches or flows. Either the actual accumulated area of each class is plotted against distance along the river from a predefined point (e.g. estuary) or the same features in percent of total area per mesohabitat type.

Intersection of maps created at different flows on the same river gives a temporal variation map (not presented here), while checking adjacency among each individual class occurrence provides us with class combination tables (as in Table IV, Table $\mathrm{V}$ and Table $\mathrm{VI}$ in chapter "Results"). This latter show most and least often appearing neighbouring class combinations found next to each other. Adjacency is important for the further population model application, as the ten different class types seem to be too detailed for this particular application. Also class combinations may sometimes be seen as complex habitat types themselves.

These methods as they reach their highest level of complexity and sophistication are used as physical river/reach describers with the ultimate purpose of providing physical habitat input for population modelling. So in the final model the spatial and temporal distribution and composition matrices will provide the direct link to population modelling. 
Table I. - Classification decision tree.

\begin{tabular}{|c|c|c|c|c|c|}
\hline criteria & surface pattern & $\begin{array}{c}\text { surface } \\
\text { gradient }\end{array}$ & $\begin{array}{l}\text { surface } \\
\text { velocity }\end{array}$ & $\begin{array}{l}\text { water } \\
\text { depth }\end{array}$ & code \\
\hline \multirow{14}{*}{ Decision } & \multirow{7}{*}{ smooth / rippled } & \multirow{3}{*}{ steep } & \multirow[t]{2}{*}{ fast } & deep & A \\
\hline & & & & shallow & \\
\hline & & & slow & $\begin{array}{l}\text { deep / } \\
\text { shallow }\end{array}$ & \\
\hline & & \multirow{4}{*}{ moderate } & \multirow[t]{2}{*}{ fast } & deep & B1 \\
\hline & & & & shallow & B2 \\
\hline & & & \multirow[t]{2}{*}{ slow } & deep & C \\
\hline & & & & shallow & $\mathrm{D}$ \\
\hline & \multirow{7}{*}{$\begin{array}{l}\text { broken / unbroken } \\
\text { standing waves }\end{array}$} & \multirow{3}{*}{ steep } & \multirow{2}{*}{ fast } & deep & $\mathrm{E}$ \\
\hline & & & & shallow & $\mathrm{F}$ \\
\hline & & & slow & $\begin{array}{l}\text { deep / } \\
\text { shallow }\end{array}$ & \\
\hline & & \multirow{4}{*}{ moderate } & \multirow[t]{2}{*}{ fast } & deep & G1 \\
\hline & & & & shallow & G2 \\
\hline & & & \multirow[t]{2}{*}{ slow } & deep & \\
\hline & & & & shallow & $\mathrm{H}$ \\
\hline
\end{tabular}

Table II. - Criteria limits.

\begin{tabular}{|c|c|c|}
\hline \multirow{2}{*}{ surface pattern } & smooth / rippled & wave height $<0.05 \mathrm{~m}$ \\
\cline { 2 - 3 } & broken / unbroken standing waves & wave height $>0.05 \mathrm{~m}$ \\
\hline \multirow{3}{*}{ surface gradient } & steeper & approx. $\pm 4 \%$. \\
\cline { 2 - 3 } surface velocity & less steep & $>0.5 \mathrm{~m} / \mathrm{s}$ \\
\cline { 2 - 3 } & fast & $<0.5 \mathrm{~m} / \mathrm{s}$ \\
\hline \multirow{3}{*}{ water depth } & slow & $>0.7 \mathrm{~m}$ \\
\hline \multirow{3}{*}{ substrate type } & deep & $<0.7 \mathrm{~m}$ \\
\cline { 2 - 3 } & shallow & $<.002 \mathrm{~mm}$ \\
\cline { 2 - 3 } & Clay (CL) & $<.02$ \\
\cline { 2 - 3 } & Silt (SI) & $<2 \mathrm{~mm}$ \\
\cline { 2 - 3 } & Sand (SA) & $<16 \mathrm{~mm}$ \\
\cline { 2 - 3 } & Gravel (GR) & $<64 \mathrm{~mm}$ \\
\cline { 2 - 3 } & Pebble (PB) & $<300 \mathrm{~mm}$ \\
\cline { 2 - 3 } & Cobble (CO) & $>300 \mathrm{~mm}$ \\
\cline { 2 - 3 } & Boulder (BO) & continuous rock \\
\hline
\end{tabular}




\section{CASE DESCRIPTIONS}

The whole development project is going to focus on five Norwegian rivers to perform as study sites. Because of the amount of data already available, and the feasibility of its location, lower Nidelva, Trondheim was included for pilot purposes. The other study sites were selected according to their relation to salmon production, physical and hydrological sizes and location. The two streams investigated and presented here are River Orkla and Ingdalselva. (Table III).

\section{RIVER ORKLA CATCHMENT}

Landscape along the river shows differences from upstream to downstream. There are four large and significantly different parts, the upper, middle and transition, and lower regions. The lower part can be identified from its wide and flat valley, and a considerable amount of farmlands. Upstream the transition zone follows between the lower and the middle regions, where river valley is steeper than in the neighbouring zones. Few agricultural areas and large forests surround the narrowing basin. Then just like at the lower region, the middle region is wide and flat and farmers occupy the floodplain. This region is slightly scattered by short rapids in the river, where the valley narrows as well. Finally in the upper region, the gradient of the riverbed is high, the valley forms a typical "V" shape (caused by erosion). The study section covers parts from the upper to the lower region (Figure 3 ).

\section{RIVER INGDALSELVA CATCHMENT}

This is a much smaller catchment with significant variation in flow throughout the year, situated next to the Orkla catchment in the northern direction. Typically short and intense floods scatter the longer quiet low flow or draught periods. The combination of the small size of the catchment and the geological structure of the valley result in rapid variations in flow after precipitation events. The river drains into Orkdalsfjorden (the Fjord of Orkla, Figure 4).

Table III. - Study sites.

\begin{tabular}{|c|c|c|c|c|c|}
\hline River & Location & Mean Flow & Catchment & $\begin{array}{c}\text { Length of } \\
\text { study section }\end{array}$ & $\begin{array}{c}\text { Detailed } \\
\text { study section }\end{array}$ \\
\hline Orkla & $\begin{array}{c}150 \mathrm{~km} \text { south- } \\
\text { west from } \\
\text { Trondheim }\end{array}$ & $67,19 \mathrm{~m}^{3} / \mathrm{s}$ & $3053 \mathrm{~km}^{2}$ & $20 \mathrm{~km}$ & $\begin{array}{c}15-20 \text { cross } \\
\text { sections }\end{array}$ \\
\hline Ingdalselva & $\begin{array}{c}50 \mathrm{~km} \text { west of } \\
\text { Trondheim }\end{array}$ & $2,62 \mathrm{~m}^{3} / \mathrm{s}$ & $102 \mathrm{~km}^{2}$ & $15 \mathrm{~km}$ & $\begin{array}{c}10-15 \text { cross } \\
\text { sections }\end{array}$ \\
\hline
\end{tabular}




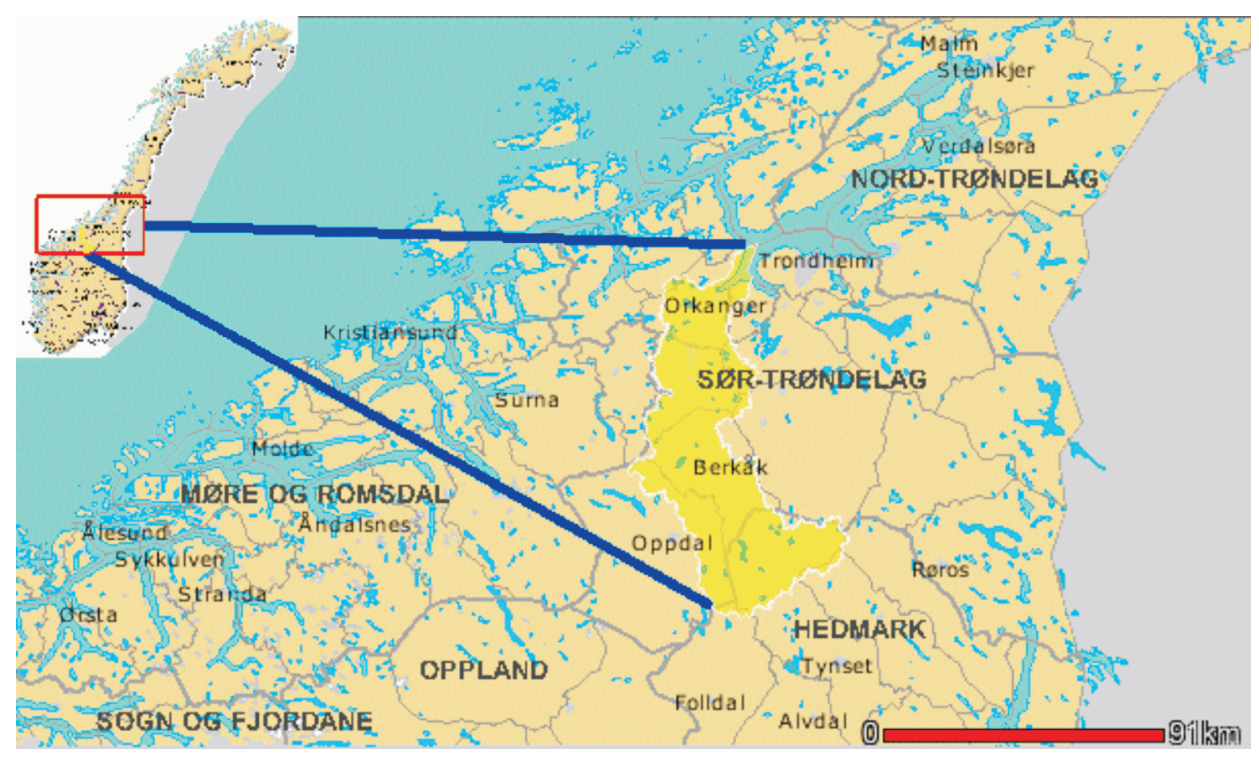

Fig. 3. - Orkla catchment.

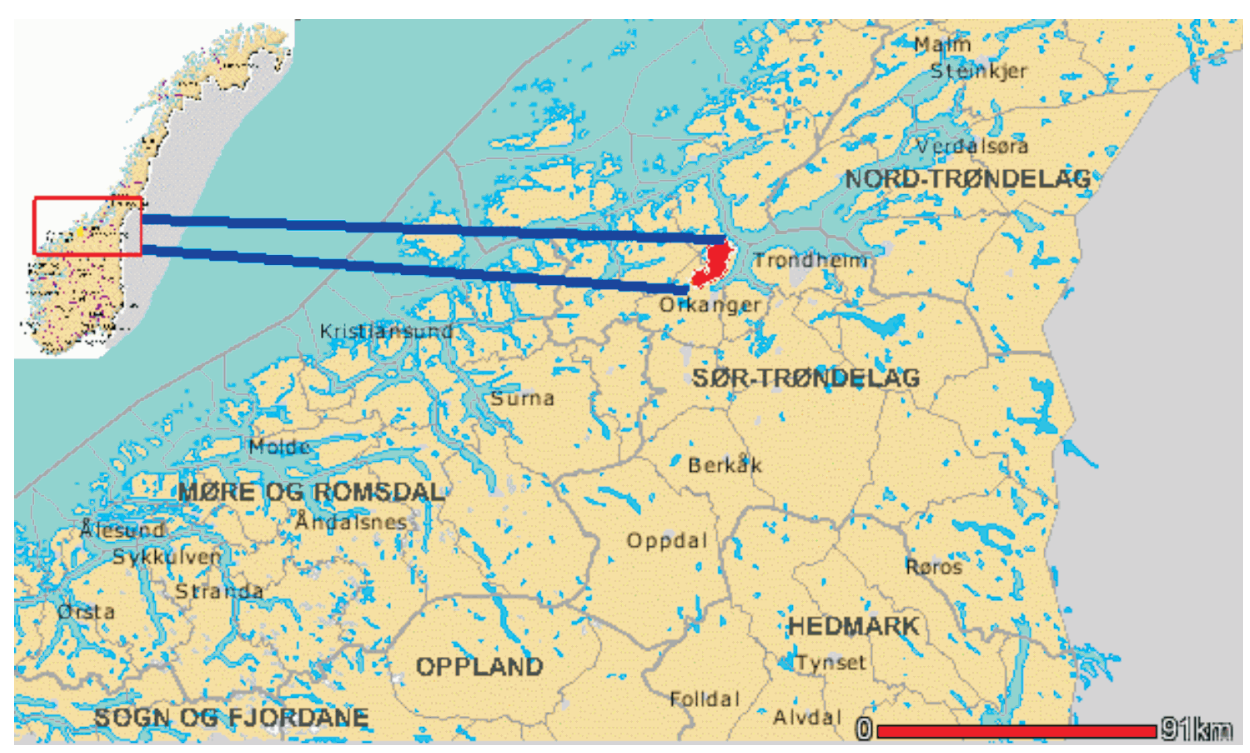

Fig. 4. - Ingdalselva catchment. 


\section{RESULTS}

Hydro-morphological classification of Ingdalselva (Figure 5) and Orkla (Figure 6) was completed during summer 2002. Class distributions were mapped at two different discharges on both rivers. Figures 5 and 6 show parts of the classified sections.
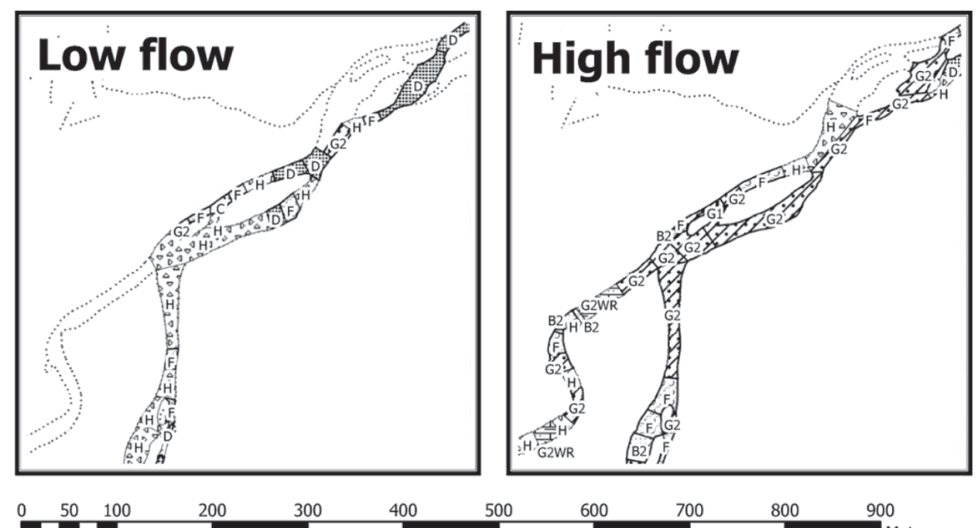

500

600

700

Fig. 5. - Ingdalselva meso-scale class mapping at two flows.

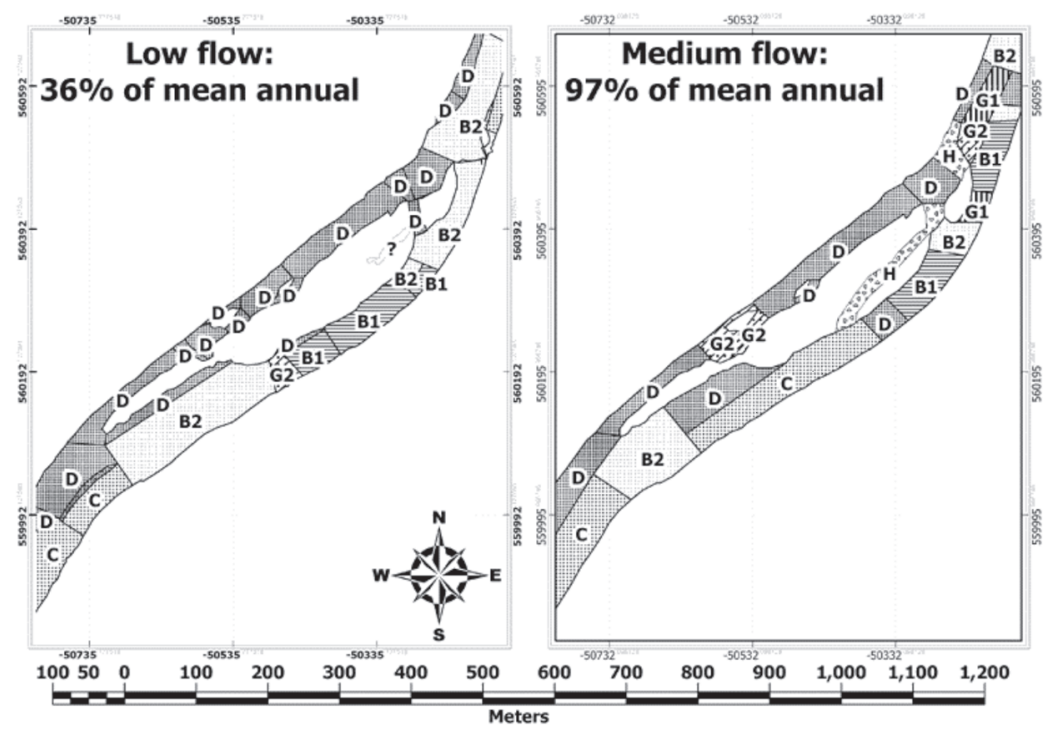

Fig. 6. - Orkla meso-scale class mapping at two flows. 
Having the classification maps digitized, by means of GIS software, spatial and statistical analyses of class distribution, sequence and accumulation becomes possible. One measure to get an overview of one river and to compare several rivers is to compare the total and average areas (horizontally projected) of each class (Figure 7 and Figure 8 ) or their proportions in relation with overall reach area (Figure 9).

Further on, accumulating the class sequences along the longitudinal section of the rivers (Figure 10 and Figure 11) would refine our vision about the distribution of the hydromorphology of the study section.

Another feature can be observed when looking at sequences of classes. In meso-habitat classification scientist often look for important class combinations, as it is believed that not only one physical feature plays a role when the individuals select their habitats. For example a pool following a glide might be of special importance resting or feeding, while a glide or riffle combined with a slower flowing shallow side part may be cru- cial for spawning or for juveniles (Table IV, Table V and Table VI).

These graphs and tables together with the sum and average class areas give to some extent a detailed overview of the studied rivers and help drawing our attention to bottlenecks, sensitive areas in habitat. Assuming a link between these hydro-morphological units and meso-sized habitat units, they show information about availability of habitat.

\section{DISCUSSION}

The discussion is structured as the comparison, and parallel analyses of the two rivers according to the same features.

First from the descriptive table (Table III), and the meso-class maps (Figure 5 and Figure 6), it is obvious that Orkla is much larger in flow and all other physical aspects than Ingdalselva. This size difference results in a more complex class distribution and larger variation of class types in the case of Orkla, and in an introduction of a special class
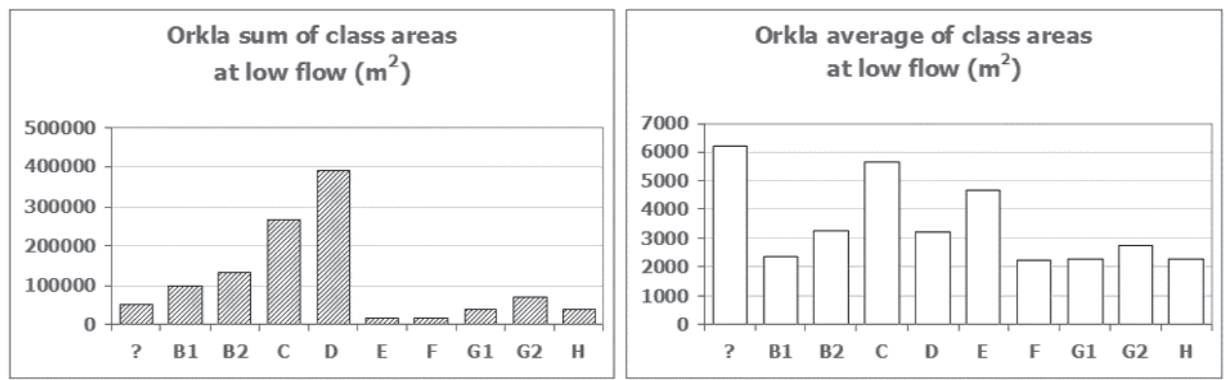

Fig. 7. - Orkla average and sum class areas. 

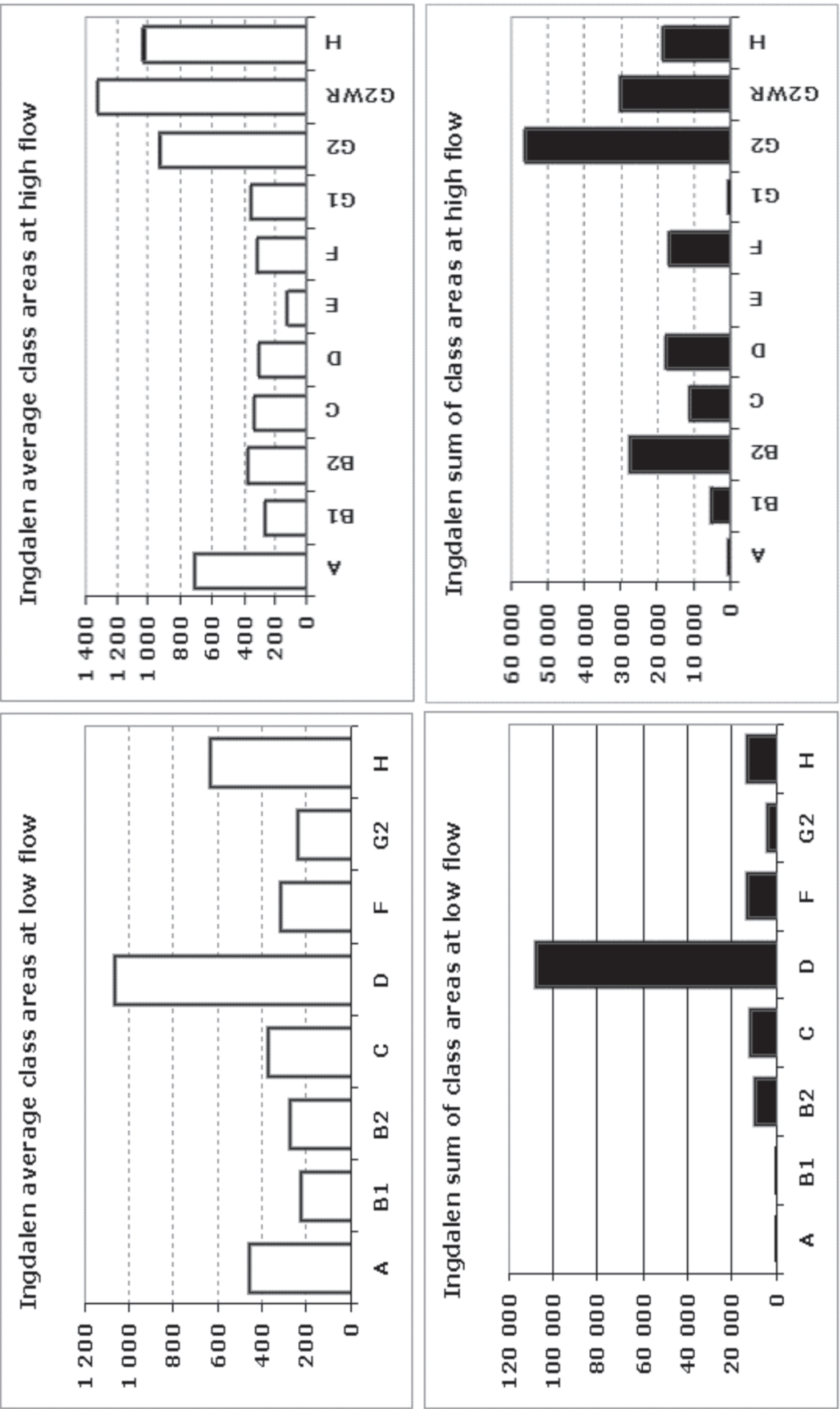

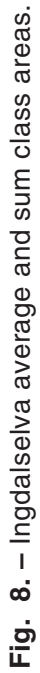



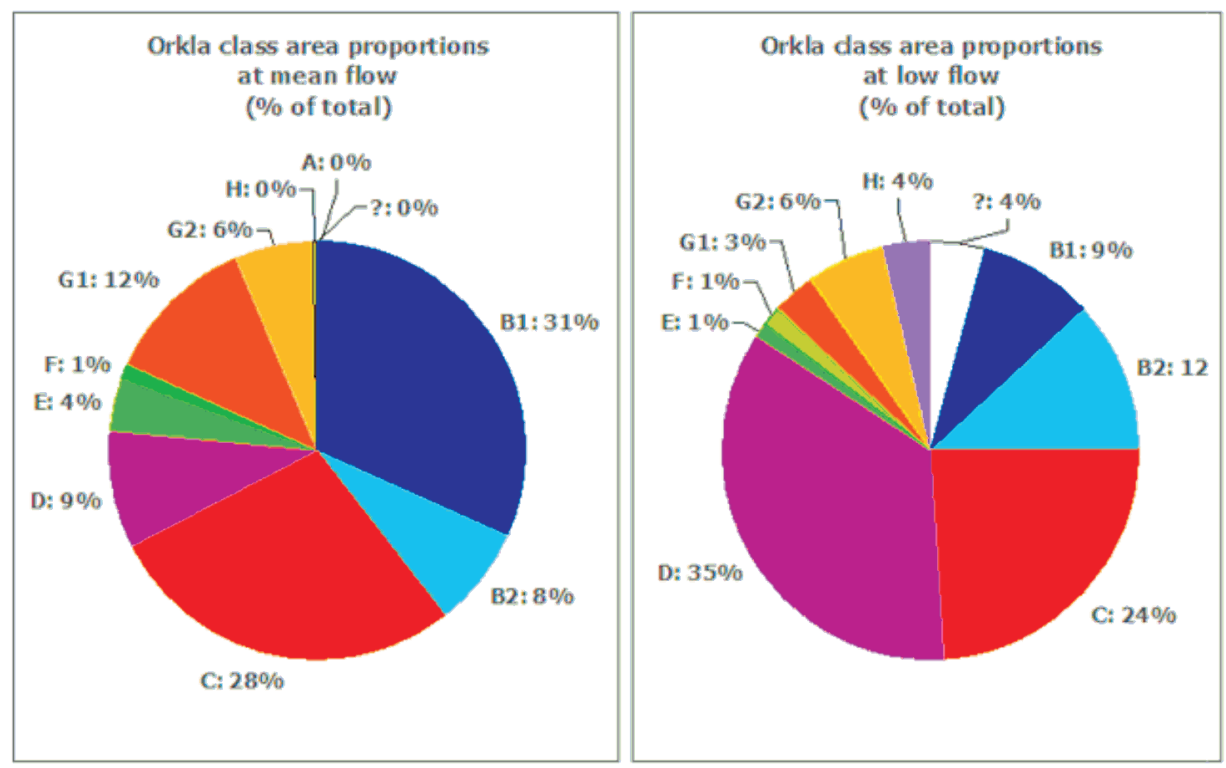

Fig. 9. - Orkla class area proportions at two flows.

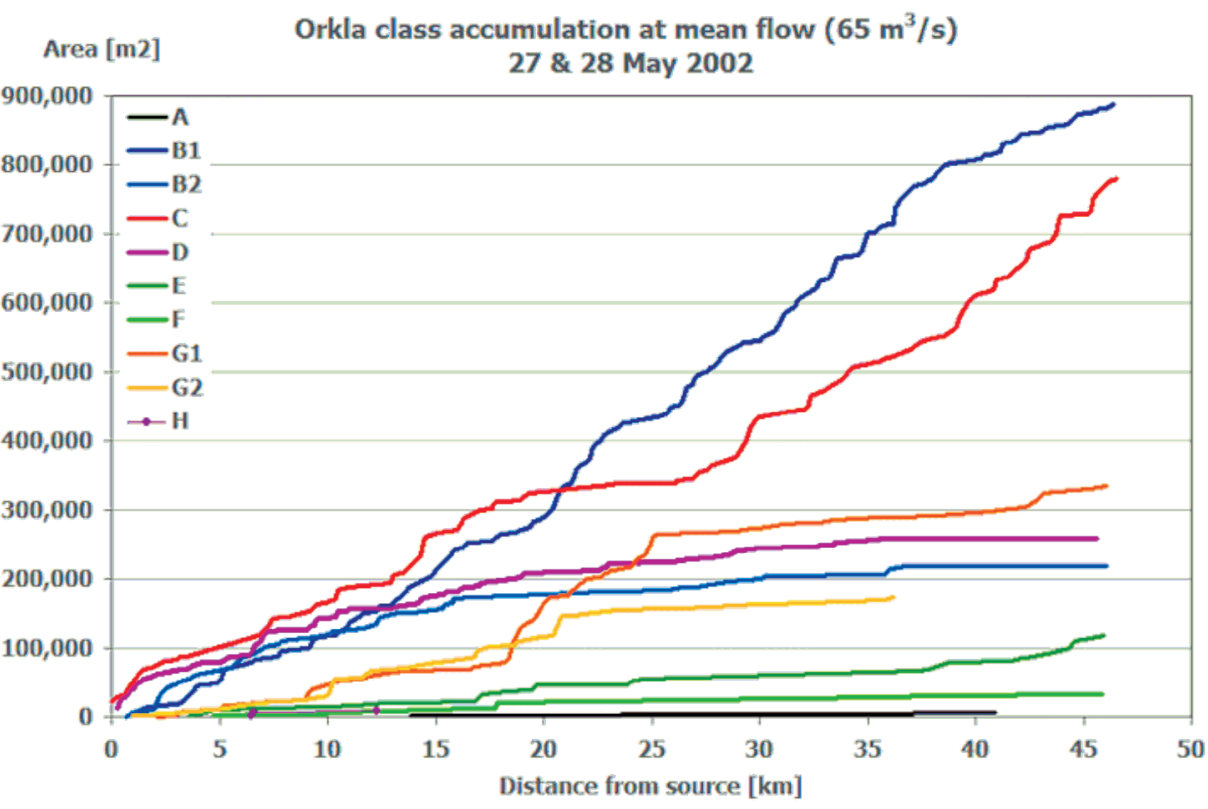

Fig. 10. - Orkla class accumulation. 

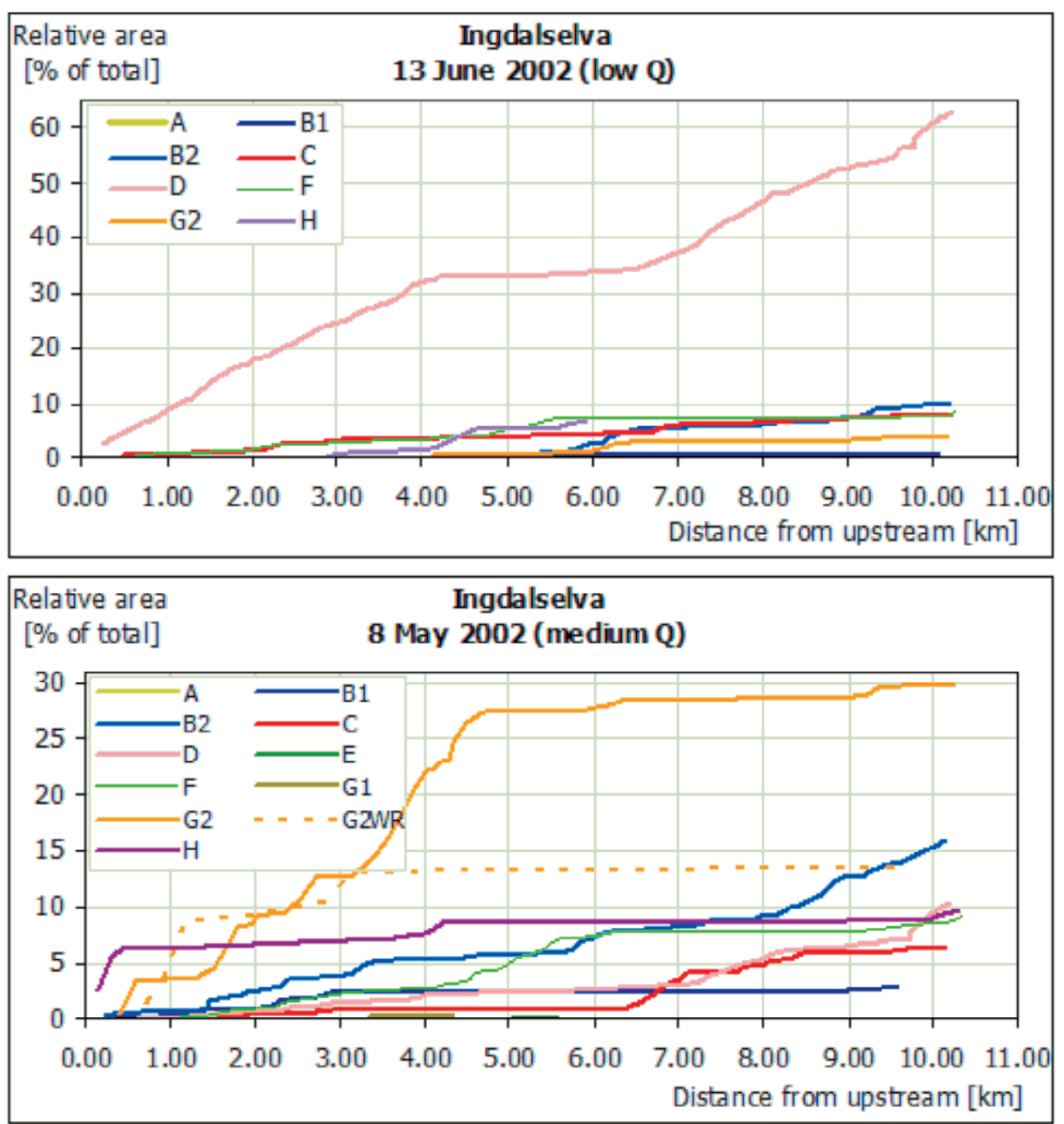

Fig. 11. - Ingdalselva class accumulation.

"G2WR" at Ingdalselva. This class is not present in the class definition, and notes a combination of large substrate (boulders) with the class "G2". This may be explained as the introduction of the second layer of substrate to the classification scheme in. It was understood that this combination possibly holds important habitat information, and therefore must be noted.
Also the shapes of classes are different. While in Orkla "Dual" and "Sandwich" layouts appear often, in Ingdalselva the dominant layout is "Mono" (Figure 2, Figure 5 and Figure 6). Further on, looking at only Ingdalselva at high and low flow we see that more classes appear at higher flow (at low flow classes "E" and "G1" are completely missing, and "A" and "B1" are very few). This 
means that the smaller river has a less scattered meso-class configuration, especially at lower discharge.

Looking at "average class area" charts we see that flow variation results in a reconfiguration of classes (Figure 8). Some classes follow the increase in discharge with their sizes ("A", "G2" and "H"), while others change in the opposite direction ("D"), and some simply remain approximately the same ("B1", "C" and "F"). Then comparing dominance among classes by sum areas it is visible that at low flow class " $D$ " is far the most dominant type, while its importance is lost to classes "G2" and "G2WR" at high flow. Further research may allow tracking the variation of the individual classes, so we could see the actual transformations and identify these - if they exist.

Important spatial information may be gained from graphs showing longitudinal class area accumulation. Here we can separate physically different sections of the studied river by finding breakpoints in the accumulation curves. Also we can see which classes dominate the different sections. In the case of Orkla one may find three different sections at the given flow at breakpoints $0 \mathrm{~km} 18 \mathrm{~km}$ $25 \mathrm{~km}$ and $46 \mathrm{~km}$ (Figure 10). The lowest part is dominated by "B1", "B2", "C" and "D" and the other classes are clearly much less in total area. Reaching the middle section the amount of class "C" gets much less than downstream, while " $\mathrm{G} 1$ " is rapidly increasing advancing upstream. By other words the lower part of Orkla is a quiet, deep pool-kind of river, and the middle part is a faster, less moderate, riffling section. Analysing the same graphs from Ingdalselva we find that the three sections appearing at low flow (breakpoints at $4 \mathrm{~km}$ and $6.5 \mathrm{~km}$ ) approximately remain at high flow, although with a different configuration and perhaps an additional breakpoint at $2 \mathrm{~km}$. At low discharge class "D" seems to be far the most important hydro-morphological unit, thereby variation of " $D$ " defines longitudinal breakpoints for the whole river. Observations at high flow show a more scattered distribution of all classes, with a dominance of "G2", "G2WR" and " $H$ " at the lowest section, of which changes to "H" is missing in the following section. From here "G2" is the most appearing class but in the most upstream section the amount of "B2" and " $C$ " is increasing rapidly.

The last tools for analysis in this study are the tables showing class sequences (Table IV, Table V and Table VI). From the tables we see how many times one class follows another. The tool needs further refinement, because only the classes following each other are counted, but not those situated next to each other, therefore not all adjacent classes are considered. Even so we see the most often and the most rarely appearing class combinations and can consider these as a fairly good description of the hydro-morphology.

Looking at Orkla (Table IV) we find numerous "B1"-"C"-"D" combinations. Not surprisingly, these appear often 
Table IV. - Class sequences on Orkla. \# of BOLD after ITALIC.

\begin{tabular}{|l|c|c|c|c|c|c|c|c|c|c|}
\hline & A & B1 & B2 & C & D & E & F & G1 & G2 & H \\
\hline A followed by & $\circ$ & 1 & 0 & 1 & 0 & 1 & 0 & 0 & 0 & 0 \\
\hline B1 followed by & 1 & $\circ$ & 23 & 32 & 25 & 6 & 7 & 22 & 13 & 1 \\
\hline B2 followed by & 0 & 18 & $\circ$ & 6 & 15 & 2 & 0 & 8 & 7 & 1 \\
\hline C followed by & 1 & 34 & 8 & $\circ$ & 26 & 4 & 1 & 6 & 2 & 0 \\
\hline D followed by & 0 & 27 & 13 & 30 & $\circ$ & 1 & 2 & 9 & 7 & 1 \\
\hline E followed by & 0 & 12 & 0 & 2 & 3 & $\circ$ & 2 & 7 & 2 & 0 \\
\hline F followed by & 1 & 2 & 4 & 2 & 1 & 5 & $\circ$ & 0 & 0 & 0 \\
\hline G1 followed by & 0 & 25 & 5 & 7 & 14 & 6 & 0 & $\circ$ & 6 & 0 \\
\hline G2 followed by & 0 & 10 & 4 & 2 & 5 & 3 & 3 & 11 & $\circ$ & 0 \\
\hline H followed by & 0 & 1 & 0 & 0 & 1 & 0 & 0 & 0 & 1 & $\circ$ \\
\hline
\end{tabular}

Table V. - Ingdalselva class sequences at low flow (13 June 2002).

\begin{tabular}{|c|c|c|c|c|c|c|c|c|}
\hline & A & B1 & B2 & C & D & F & G2 & H \\
\hline A followed by & $\circ$ & 0 & 1 & 0 & 0 & 0 & 0 & 0 \\
\hline B1 followed by & 0 & $\circ$ & 0 & 1 & 0 & 2 & 0 & 0 \\
\hline B2 followed by & 1 & 1 & $\circ$ & 1 & 21 & 1 & 6 & 1 \\
\hline C followed by & 0 & 0 & 1 & $\circ$ & 15 & 13 & 0 & 2 \\
\hline D followed by & 0 & 1 & 18 & 23 & $\circ$ & 16 & 3 & 8 \\
\hline F followed by & 0 & 1 & 2 & 4 & 20 & $\circ$ & 6 & 6 \\
\hline G2 followed by & 0 & 0 & 8 & 1 & 4 & 1 & $\circ$ & 2 \\
\hline H followed by & 0 & 0 & 2 & 1 & 8 & 7 & 1 & $\circ$ \\
\hline
\end{tabular}

Table VI. - Ingdalselva class sequences at high flow (8 May 2002).

\begin{tabular}{|c|c|c|c|c|c|c|c|c|c|c|c|}
\hline & A & B1 & B2 & C & D & E & F & G1 & G2 & G2WR & H \\
\hline A followed by & $\circ$ & 0 & 0 & 0 & 0 & 0 & 1 & 0 & 0 & 0 & 0 \\
\hline B1 followed by & 1 & $\circ$ & 2 & 2 & 2 & 0 & 9 & 1 & 0 & 1 & 0 \\
\hline B2 followed by & 0 & 8 & $\circ$ & 5 & 22 & 1 & 8 & 0 & 11 & 3 & 5 \\
\hline C followed by & 0 & 0 & 3 & $\circ$ & 17 & 0 & 2 & 0 & 4 & 1 & 1 \\
\hline D followed by & 0 & 2 & 22 & 19 & $\circ$ & 0 & 5 & 0 & 5 & 2 & 3 \\
\hline E followed by & 0 & 0 & 0 & 0 & 0 & $\circ$ & 3 & 0 & 0 & 0 & 0 \\
\hline F followed by & 0 & 1 & 14 & 1 & 5 & 1 & $\circ$ & 0 & 17 & 4 & 1 \\
\hline G1 followed by & 0 & 0 & 1 & 0 & 0 & 0 & 1 & $\circ$ & 1 & 0 & 0 \\
\hline G2 followed by & 0 & 1 & 17 & 1 & 8 & 0 & 13 & 2 & $\circ$ & 0 & 3 \\
\hline G2WR followed by & 0 & 4 & 2 & 0 & 2 & 1 & 0 & 0 & 2 & $\circ$ & 0 \\
\hline H followed by & 0 & 1 & 3 & 0 & 2 & 0 & 3 & 0 & 5 & 0 & $\circ$ \\
\hline
\end{tabular}


at medium sized, good fishing rivers like this, describing the spots where glides flow into a pools leaving narrow stretches of shallow water on the sides. The only other class combination which is worth mentioning is perhaps "G1"-"B1". This is more or less like a moderately steep run of water reaching a glide, and can be seen as a preceding to the usual combination of glides-pools above.

Ingdalselva is both similar to and different from Orkla. In Ingdalselva, we see "B2"-"D" together with "D"-"C" sequences often at both discharges. "B2" is basically a shallow glide and "D" may be considered as a shallow pool (or small pool at such a small stream), so this is very similar to those found at Orkla, only these are smaller in depth due to stream size. The high amount of "G2"-"B2" at high flow looks also familiar from the larger river ("G1"-"B1" there). But we see a surprising combination of "F"-" $D$ " at low flow with considerable amount. This does not appear either at Orkla or at Ingdalselva at high discharge, and describes the special feature of this stream. This combination probably shows the scattered shape of the longitudinal river profile, where often short, steep sections are followed by longer and wider channels with gentle slopes.

The classification has the final goal to provide physical habitat description for the population model. Based on the needs for classes identified in the population model the meso-habi- tat method classification used will be simplified by grouping "C" and "B1" together, "B2" will be separate, "D" will be added to "C" if parallel, "G2" and " $\mathrm{H}$ " will be added and " $\mathrm{E}$ " and " $\mathrm{F}$ " will also be added together. However this does not mean that the system is too complicated in its present form. Other applications may require a different kind of grouping, therefore the present version will be kept as template for later studies.

\section{SUMMARY}

The linking of meso-scale hydromorphological units to meso-habitats is useful for fish population modelling. The linking method can be based on knowledge both of river hydraulics and river habitats from previous micro-habitat studies. Mapping of distribution of meso-scale hydro-morphological units at different flows along whole rivers or longer reaches can describe habitats of these sections. Overall channel formation, critical flow variations, local bottlenecks may be identified, without assuming validity of local (small scale) habitat distribution to larger dimensions in a statistically questionable way. For use in population modelling further simplifications are necessary. Development of the method is ongoing, but is already useful in its present stage in river management as shown by examples. 


\section{REFERENCES}

Alfredsen, K. (1997) - A modelling system for estimation of impacts on fish habitat. In 27th International Association for Hydraulic Research Congress : Water for a changing society: pp. 6. IAHR, San Francisco.

Bisson, P.A., Nielsen, J.L., Palmason, R.A. \& Grove, L.E. (1981) - A system of naming habitat types in small streams, with examples of habitat utilization by salmonids during low streamflow. In Symposium on Acquisition and Utilization of Aquatic Habitat Inventory Information, Portland, USA.

Bovee, K.D. (1982) - A guide to stream habitat analysis using the Instream Flow Incremental Methodology, Rep. No. 12. Western Energy and Land Use Team Office of Biological Services Fish and Wildlife Service, U.S. Dept. of the Interior, Washington, D.C.

Cohen, P., Andriamahefa, H. \& Wasson, J.G. (1998) - Towards a Regionalization of Aquatic Habitat: Distribution of Mesohabitats at the Scale of a Large Basin - Regulated rivers, 14(5) : 14.

EU (2000) - Directive of the European Parliament and of the Council establishing a framework for Community action in the field of water policy: pp. 151, Bruxelles.

Hardy, T.B. (1995) - Habitat typing and habitat mapping. In Workshop on advanced techniques for instream flow assessments, Prague, Czech Republic.

Hawkins, C.P., Kershner, J.L., Bisson, P.A., Bryant, M.D., Decker, L.M., Gregory, S.V., McCullough, D.A., Overton, C.K., Reeves, G.H., Steedman, R.J. \& Young, M.K. (1993) - A hierarchical approach to classifying stream habitat features - Fisheries, 18(6) : 3-11.

Jowett, I.G. (1993) - A method for objectively identifying pool, run, and riffle habitats from physical measurements -
New Zealand journal of marine and freshwater research, 27(2) : 241-248.

Kemp, J., Harper, D.M. \& Crosa, G.A. (1999) - Use of 'Functional Habitats' to Link Ecology with Morphology and Hydrology in River Rehabilitation Aquatic conservation: marine and freshwater ecosystems, 9(1) : 159.

Kershner, J.L. \& Snider, W.M. (1992) Importance of habitat-level classification system to design instream flow studies. In River conservation and management (eds P.J. Boon, P. Carlow \& G.E. Petts) : 179-193. John Wiley \& Sons.

Maddock, I. \& Bird, D. (1996) - The application of habitat mapping to identify representative PHABISM sites on the River Tavy, Devon UK. In 2nd International Symposium on Habitat Hydraulics (eds M. Leclerc, H. Capra, S. Valentin, A. Boudreault \& Y. Côté), Vol. B: pp. 203-214. INRS-EAU; FQSA; IAHR-AIRH, Québec, Canada.

Maddock, I. (1999) - The importance of physical habitat assessment for evaluating river health - Freshwater Biology, 41(2) : 373-391.

Mader, H., Meixner, H. \& Habersack, H. (1999) - Cluster analysis, a tool for setting up river typologies. In 3rd International Symposium on Ecohydraulics, Salt Lake City, UT, USA.

Parasiewicz, P. (2001) - MesoHABSIM : A concept for application of instream flow models in river restoration planning - Fisheries, 26(9) : 6-13.

Raven, P.J., Holmes, N.T.H., Dawson, F.H., Fox, P.J.A., Everard, M., Fozzard, I.R. \& Rouen, K.J. (1998) - River habitat quality, the physical character of rivers and streams in the UK and Isle of Man, Rep. No. 2. Environment Agency United Kingdom.

Rosgen, D. (1996) - Applied river morphology, 2 edn. Wildland Hydrology, Pagosa Springs, Colorado, USA

Stalnaker, C.B., Lamb, B.L., Henriksen, J., Bovee, K.D. \& Bartholow, J. (1995) 
- The Instream Flow Incremental Methodology. A primer for IFIM, Rep. No. 29. U.S Department of Interior, National Biological Service, Fort Collins, Colorado, USA.

Takahashi, G. (1994) - Basis for classification of riffle-pool components and its application. In 1st international symposium on habitat hydraulics, Vol. 1 : pp. 294-304, Trondheim, Norway.

Vadas, R.L.J. \& Orth, D.J. (1998) - Use of physical variables to discriminate vi- sually determined mesohabitat types in Nort American streams - Rivers: Studies in the Science, Environmental Policy and Law of Instream Flow, 6(3) : 143-159.

Van Beurden, A.U.C.J. \& Douven, W.J.A.M. (1999) - Aggregation issues of spatial information in environmental research - International Journal of Geographical Information Science 13, no. 5. 